\title{
Preoperative Biometry and Uncorrected Visual Outcome Following Cataract Surgery at a Teaching Hospital at Western Part of Nepal
}

\author{
Thapa $\mathrm{BB}^{1}$, Adhikari BP${ }^{1}$, Gurung $\mathrm{NK}^{1}$, Verma $\mathrm{JK}^{1}$
}

\section{ABSTRACT}

Introduction: Proper preoperative biometry in cataract surgery provides expected postoperative uncorrected visual outcome. Astigmatism is one of the major problems to achieve best postoperative unaided visual acuity. Aims: To determine the distribution of biometric parameter and unaided visual outcome in the cataract patients operated at Nepalgunj medical college, Banke, Nepal. Methods: The patients who underwent cataract surgery between January 2019 and December 2020 at Nepalgunj medical college were studied. Patient's demographic parameter, keratometric value, anterior chamber depth, lens thickness and axial length data, type of surgery, preoperative and post-operative visual acuity and other clinical details were collected and analyzed. Results: This study enrolled 261 eyes of 261 patients who had undergone cataract surgery. The mean age of patients was $60.8 \pm 14.62$ years. The mean corneal astigmatism was $1.30 \pm 1.43 \mathrm{D}$. Corneal astigmatism was higher than $1.00 \mathrm{D}$ in almost $40 \%$ of cases. With-therule astigmatism was the most common type (46.4\%) of astigmatism observed in this study. The mean average keratometry was 44.83 $\pm 2.05 \mathrm{D}$. The mean preoperative LogMAR VA of $1.52 \pm 0.83$ improved to $0.48 \pm 0.48$ postoperatively without statistically significant differences between manual small incision cataract surgery and phacoemulsification technique $(p=0.496)$. Conclusions: The biometric data helps to improve surgical procedure and select most appropriate intraocular lens to attain maximal postoperative uncorrected visual acuity following cataract surgery. This study found superior convention incision is better for cataract surgery with equivalent visual outcome following manual small incision cataract surgery and phacoemulsification.

Keywords: Astigmatism, Biometry, Cataract surgery, Visual outcome

Authors:

\author{
1. Dr. Bikram Bahadur Thapa \\ 2. Prof. Bashu Prasad Adhikari \\ 3. Prof. Nanda Kumari Gurung \\ 4. Mr. Jitendra Kumar Verma \\ ${ }^{1}$ Department of Ophthalmology, Nepalgunj Medical College and Teaching Hospital, Nepalgunj, Banke
}

\section{Address for Correspondence:}

\author{
Dr. Bikram Bahadur Thapa \\ Assistant Professor \\ Department of Ophthalmology \\ Nepalgunj Medical College and Teaching Hospital \\ Nepalgunj, Banke \\ Email: drbbthapa@gmail.com
}

\section{INTRODUCTION}

Phacoemulsification is the preferred technique for the treatment of cataract worldwide whereas small incision cataract surgery (SICS) is a cost effective alternative in developing nations. ${ }^{1,2}$ Accurate measurements of axial length $(A L)$, keratometry $(K)$, and anterior chamber depth $(A C D)$ are needed to obtain the precise intraocular lens (IOL) power. To obtain good uncorrected visual outcome, an accurate power IOL must be implanted..$^{1-4}$ Postoperative visual acuity, ability to work, quality of life, and economic rehabilitation can all be used to assess the success of cataract surgery. The visual outcome has a significant impact on the patients' visual satisfaction, vision-related quality of life, ability to work in everyday activities, and overall productivity. ${ }^{5}$ World Health Organization (WHO) suggest poor visual outcome for best corrected visual acuity (BCVA) of $<6 / 60$, borderline for $<6 / 18$ and good for $\geq 6 / 18$. As per $W H O$, to consider a successful visual outcome at least $80 \%$ of the operated eyes should have a VA of $6 / 6-$ $6 / 18$ after surgery without any correction, and at least $90 \%$ of the eyes after best correction. ${ }^{6}$ The concurrent sight impairing eye diseases, early surgical complications, inadequate optical correction, or long-term complications are the main reason of poor postoperative visual outcome. ${ }^{7}$ There are studies of preoperative biometry and corneal astigmatism on cataract patients and visual outcome after surgery. ${ }^{1,8}$ These studies showed geographic, ethnic and other variations. Therefore, the aim of our study was to determine the corneal astigmatism, distribution of biometric parameters and the uncorrected visual outcome on postoperative day in the cataract patients.

\section{METHODS}

This was a prospective hospital based study conducted at Nepalgunj Medical College and Teaching Hospital in the department of Ophthalmology from January 2019 to 
December 2020 after ethical approval by the institutional review committee. All patients who were age above 15 year were included in the study. Patients with history of other ocular surgeries before cataract surgery such as refractive surgery, trabeculectomy and retinal surgery, corneal diseases, ocular inflammation, retinal diseases, glaucoma, coloboma, microphthalmus and ocular trauma were excluded. History and routine eye examinations findings before surgery including visual acuity, retinoscopy, tonometry, slit lamp and dilated fundus evaluation were collected from casesheet. The procedure processes were fully explained to each patient and written informed consent was obtained as documented on casesheet. Biometry data including Ocular axial length $(A L)$, anterior chamber depth (ACD) and lens thickness (LT) of each cataract affected eye were measured with the ultrasound A\&B scan(compact touch Quantel medical France). Keratometry (K) and corneal astigmatism were measured using autorefractokeratometer (Shin Nippon AccurefK-90 Rexxam Co. Itd, Japan). The patients were divided into 7 groups on the basis of age as follows: $\leq 30$ years, $31-40$ years, $41-50$ years, $51-60$ years, $61-$ 70 years, $71-80$ years, and $>81$ years. All eyes were stratified into 4 groups based on $\mathrm{AL}$ as follows: shorter than $22.0 \mathrm{~mm}$, $22.0-24.5 \mathrm{~mm}, 24.5 \mathrm{~mm}-26.0 \mathrm{~mm}$ and longer than $26.0 \mathrm{~mm}$. The types of surgery and IOL implanted were recorded. Complications during and following surgery were collected. The Visual acuity, IOP, and other findings on postoperative day were collected. Continuous variables were expressed as the mean \pm standard deviation for those displaying normal distribution. Paired T-test was applied to compare the mean. Statistical analysis was performed using SPSS software version 21. P-values less than 0.05 were considered statistically significant.

\section{RESULTS}

This study enrolled 261 eyes of 261 patients. The mean age of patient was $60.8 \pm 14.62$ (range $15-90$ ) years. The male and female ratio was $1: 1.23$. The $85 \%$ were Nepalese patients whereas $15 \%$ were Indian nationals as shown in Table I.

\begin{tabular}{|c|c|c|c|c|}
\hline Age (years) & Frequency & Percentage (\%) & Mean \pm SD & Range \\
\hline$\leq 30$ & 10 & 3.8 & $60.80 \pm 14.62$ & \multirow{7}{*}{$15-90$} \\
\hline $31-40$ & 13 & 5 & & \\
\hline $41-50$ & 28 & 10.7 & & \\
\hline $51-60$ & 67 & 25.7 & & \\
\hline $61-70$ & 89 & 34.1 & & \\
\hline $71-80$ & 41 & 15.7 & & \\
\hline$\geq 81$ & 13 & 5 & & \\
\hline Gender & & & M: F ratio & \\
\hline Male & 117 & 44.83 & $1: 1.23$ & \\
\hline Female & 144 & 55.17 & & \\
\hline \multicolumn{5}{|l|}{ Nationality } \\
\hline Nepalese & 222 & 85.06 & & \\
\hline Indian & 39 & 14.96 & & \\
\hline
\end{tabular}

Table I: Demographic profile of cases with cataract
The preoperative visual acuity (VA) was < 6/60 in 136(52\%) cases and $\leq 6 / 24$ in $247(95.6 \%)$ of cases. Only $5.4 \%$ of cases were operated for cataract when preoperative VA was $\geq 6 / 18$ due to glare, photophobia and other symptoms. The mean LogMAR preoperative VA was $1.52 \pm 0.83$. The mean axial length was $23.01 \pm 1.23 \mathrm{~mm}$, mean Anterior Chamber depth (ACD) was $2.94 \pm 0.48 \mathrm{~mm}$ and mean Lens Thickness was $3.73 \pm 0.96 \mathrm{~mm}$. The mean average keratometry was $44.83 \pm 2.05 \mathrm{D}$. The mean astigmatism was $1.30 \pm 1.43$ as shown in table II

\begin{tabular}{|c|c|c|c|}
\hline $\begin{array}{l}\text { Uncorrected visual } \\
\text { acuity }\end{array}$ & Frequency (N) & Percentage (\%) & $\begin{array}{l}\text { Mean } \\
V A \pm S D\end{array}$ \\
\hline$\geq 6 / 18$ & 14 & 5.4 & \multirow{5}{*}{$1.52 \pm 0.83$} \\
\hline $6 / 24-6 / 60$ & 111 & 42.5 & \\
\hline $5 / 60-3 / 60$ & 22 & 8.4 & \\
\hline$<3 / 60$ & 114 & 43.7 & \\
\hline $\begin{array}{l}\text { Biometric } \\
\text { Parameter }\end{array}$ & Range & Mean $\pm S D$ & \\
\hline $\begin{array}{l}\text { Anterior chamber } \\
\text { Depth }\end{array}$ & $2.09-4.16 \mathrm{~mm}$ & $2.94 \pm 0.48 \mathrm{~mm}$ & \\
\hline Lens Thickness & $1.13-5.12 \mathrm{~mm}$ & $3.73 \pm 0.96 \mathrm{~mm}$ & \\
\hline Axial Length & $18.42-32.35 \mathrm{~mm}$ & $23.01 \pm 1.23 \mathrm{~mm}$ & \\
\hline $\begin{array}{l}\text { Average } \\
\text { keratometry }\end{array}$ & $40.00-54.00 \mathrm{D}$ & $44.83 \pm 2.05 \mathrm{D}$ & \\
\hline corneal astigmatism & $0.00-8.25 \mathrm{D}$ & $1.30 \pm 1.43 \mathrm{D}$ & \\
\hline
\end{tabular}

Table II: Preoperative ocular biometry and visual acuity of patients

Corneal astigmatism of $0.1-1.00 \mathrm{D}$ was the most common of range values (53.3\%), followed by $1.01-2 \mathrm{D}(23.8 \%)$. Thedistributions of corneal astigmatism for all patients are shown in figure 1.

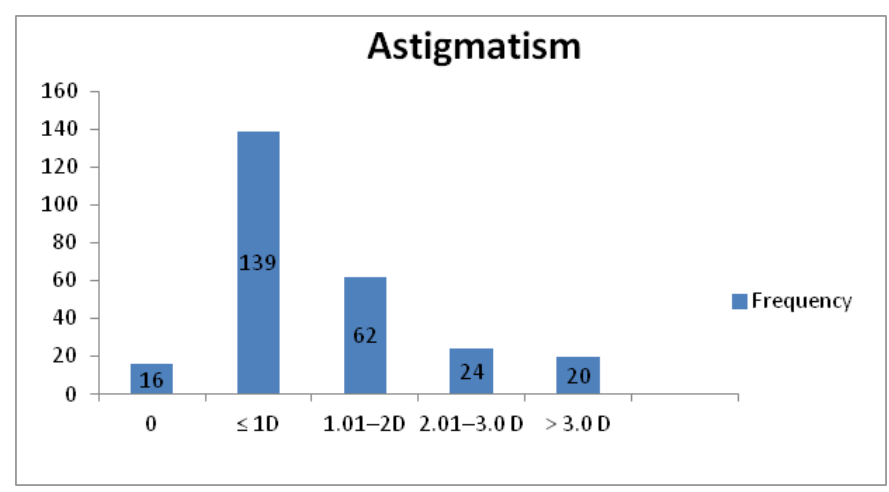

Figure 1: Distribution of corneal astigmatism

Corneal astigmatism was with-the-rule (WTR, the steepest meridian of the cornea being within $90 \pm 30$ degrees) in 121 eyes $(46.4 \%)$, against-the-rule (ATR, the steepest meridian of the cornea being within $180 \pm 30$ degrees) in 82 eyes (31.4\%) and oblique (steepest meridian between 30 and 60 degrees or 120 and 150 degrees) in 42 eyes (16.1\%). The WTR astigmatism was the most common type as shown in figure 2 . 


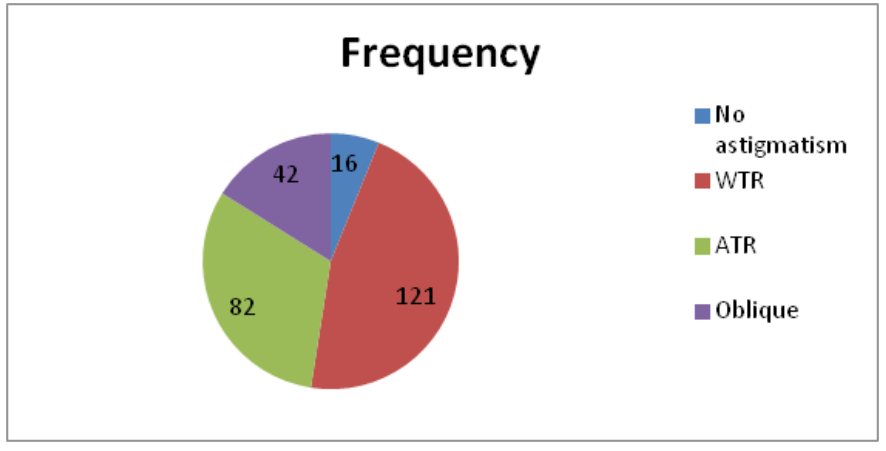

Figure 2: Type of corneal astigmatism

The average keratometry values increased with age. The AL and $A C D$ values showed not much variation with age; whereas lens thickness showed gradually increasing trend with age and corneal astigmatism showed first a decline andthen a rising trend. It is found that male had longer eyes with higher corneal astigmatism than female. Age and gender wise distribution of biometric parameter is tabulated in table III.

\begin{tabular}{|c|c|c|c|c|c|c|}
\hline $\begin{array}{c}\text { Age } \\
\text { (years) }\end{array}$ & $\begin{array}{c}\text { Frequency } \\
\text { (N) }\end{array}$ & $\begin{array}{l}\text { Astigmatism } \\
\text { (D) }\end{array}$ & $\begin{array}{c}\text { Anterior } \\
\text { chamber } \\
\text { depth }(m m)\end{array}$ & $\begin{array}{l}\text { Lens } \\
\text { thickness } \\
(\mathrm{mm})\end{array}$ & $\begin{array}{l}\text { Axial } \\
\text { length } \\
(\mathrm{mm})\end{array}$ & $\begin{array}{l}\text { Average } \\
\text { keratometry } \\
\text { (D) }\end{array}$ \\
\hline$\leq 30$ & 10 & $1.63 \pm 1.87$ & $2.66 \pm 1.02$ & $2.51 \pm 1.10$ & $23.09 \pm 2.62$ & $43.00 \pm 2.00$ \\
\hline $31-40$ & 13 & $0.71 \pm 0.43$ & $3.12 \pm 0.30$ & $3.89 \pm 1.11$ & $23.44 \pm 0.91$ & $44.00 \pm 2.00$ \\
\hline $41-50$ & 28 & $1.07 \pm 0.80$ & $2.94 \pm 0.68$ & $3.37 \pm 1.14$ & $23.12 \pm 0.87$ & $45.00 \pm 2.00$ \\
\hline $51-60$ & 67 & $1.32 \pm 1.52$ & $2.99 \pm 0.40$ & $3.86 \pm 0.77$ & $22.92 \pm 1.39$ & $45.00 \pm 2.00$ \\
\hline $61-70$ & 89 & $1.24 \pm 1.55$ & $2.92 \pm 0.42$ & $3.74 \pm 0.91$ & $22.94 \pm 1.40$ & $45.00 \pm 2.00$ \\
\hline $71-80$ & 41 & $1.64 \pm 1.56$ & $2.98 \pm 0.40$ & $4.04 \pm 0.83$ & $23.00 \pm .1 .03$ & $45.00 \pm 2.00$ \\
\hline$\geq 81$ & 13 & $1.50 \pm 0.85$ & $2.82 \pm 0.39$ & $3.52 \pm 1.03$ & $23.11 \pm 0.74$ & $44.00 \pm 1.00$ \\
\hline Gender & & & & & & \\
\hline Female & 144 & $1.22 \pm 1.32$ & $2.88 \pm 0.47$ & $3.60 \pm 0.99$ & $22.80 \pm 0.96$ & $45.00 \pm 2.00$ \\
\hline Male & 117 & $1.41 \pm 1.56$ & $3.02 \pm 0.48$ & $3.89 \pm 0.89$ & $23.28 \pm 1.46$ & $45.00 \pm 2.00$ \\
\hline & 261 & $1.30 \pm 1.43$ & $2.94 \pm 0.48$ & $3.73 \pm 0.96$ & $23.01 \pm 1.23$ & $44.83 \pm 2.05$ \\
\hline
\end{tabular}

\section{Table III: Age and gender wise distribution of biometric parameter}

The $\mathrm{AL}$ in the majority of eyes was between 22.0 and $24.5 \mathrm{~mm}$ (81.2\%). The mean ACD and LT increases as the AL increases. The keratometry values decreases with an increase in the AL. The mean corneal astigmatismincreases with increasing ALs as showed in table IV.

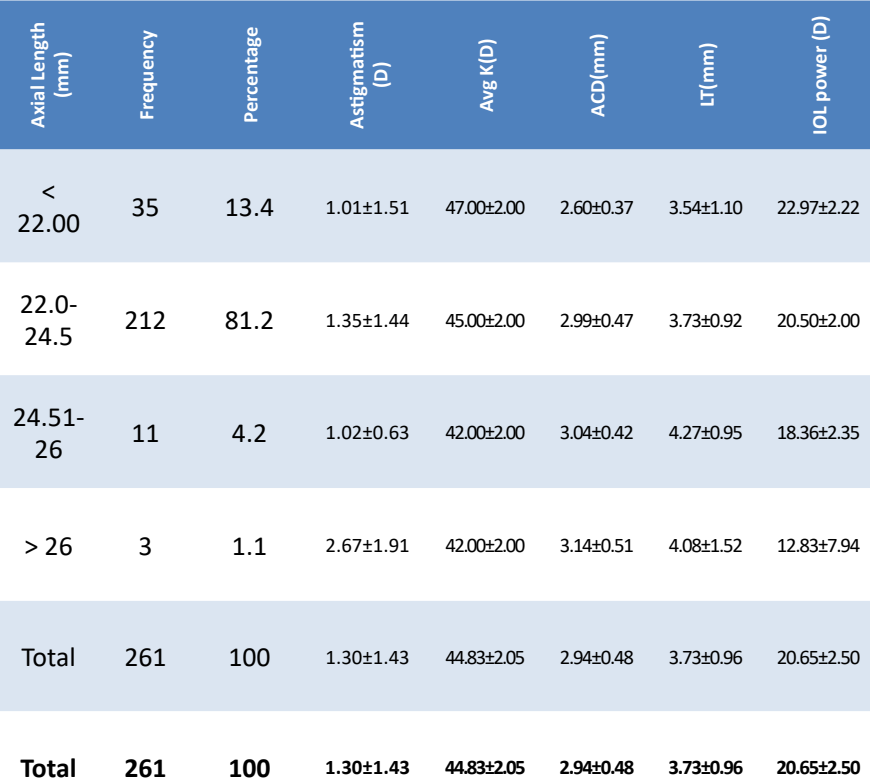

Table IV: Distribution of parameter for different axial length

The 204(78.2\%) eyes were operated by Manual small incision cataract surgery (SICS) with rigid PMMA posterior chamber intraocular lens(FH106, Fred Hollow IOL Lab, Kathmandu, Nepal) implantation, whereas 57 (21.8\%) eyes were operated by Phacoemulsification with hydrophilic acrylic foldable posterior chamber intraocular lens( RYCF-6, Care Group Soluton Pvt LTD, Vadodara, Gujarat, India) implantation. The power of IOL implanted ranged from 8.00-30.00 D(mean = $20.65 \pm 2.5)$. The postoperative day uncorrected visual acuity is tabulated on table $V$ which showed slightly better result with phacoemulsification $(0.44 \pm 0.48)$ than SICS $(0.49 \pm 0.49)$ but difference was not statistically significant $(p=0.496$, paired $T$ test) as shown in Table $\mathrm{V}$.

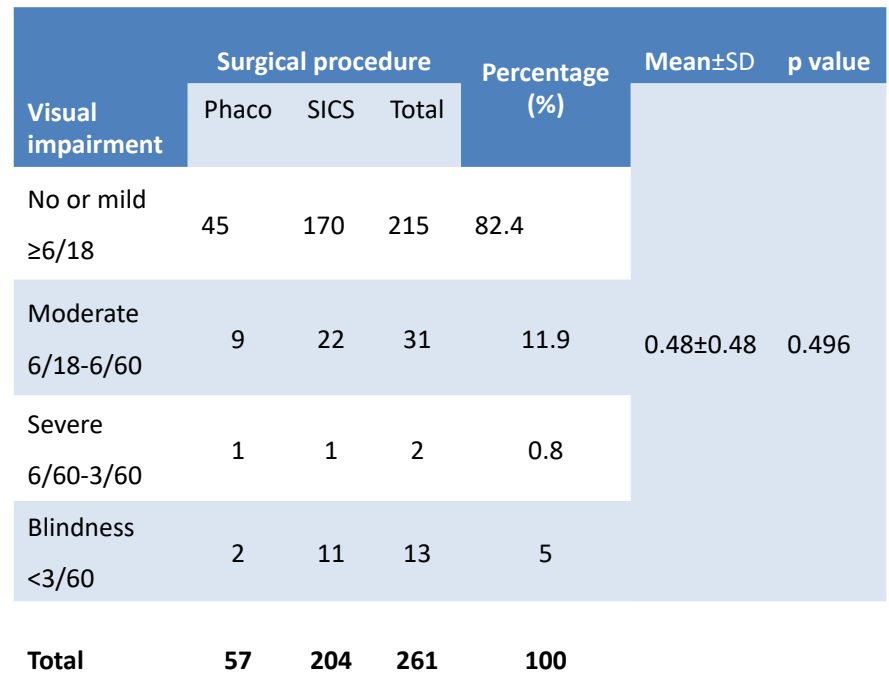

Table V: Visual outcome on postoperative day as WHO classification

The cause of $U C V A<3 / 60$, in 5 patients on postoperative day 
includes corneal edema in two eyes, glaucomatous optic atrophy in one eye, advanced diabetic eye disease in one eye and optic atrophy in one eye.

\section{DISCUSSION}

Preoperative corneal astigmatism and mismatched ocular biometry are the main obstacles to obtain a satisfactory postoperative uncorrected visual acuity for patients undergoing uncomplicated cataract surgery, as the surgery eliminates lenticular astigmatism; presuming minimal surgically induced astigmatism. Thus preoperative corneal astigmatism and mismatched biometry leads to patient dissatisfaction. ${ }^{8,9}$ The prevalence and type of preoperative corneal astigmatism in cataract patients has been identified in several countries and is taken into consideration during surgery. ${ }^{1,8-13}$ Western Nepal has huge burden of cataract with number of cataract surgery increasing each year., 10,11 We compared the results of present study with the study from various regions of Nepal as well as of other countries. ${ }^{1,8,10,12,14}$ It is found that the average corneal power in patients of NGMC is greater than that in other different regions of Nepal and other countries. The axial lengths of patients of this study were comparable Bheri, Karnali, Bagmati zone of Nepal and Vietnam whereas Chinese eyes were longer than other studies. ${ }^{1,8,10,12,14}$ The highest corneal astigmatism in our study was 8.25 D as seen in the Chinese studies and study on Bheri zone of Nepal. ${ }^{1,8}$ The $59.4 \%$ of cataract patients has astigmatism lesser than $1.00 \mathrm{D}$ in this study comparable to the findings of Thapa et $\left.\mathrm{al}^{8}(67 \%)\right)$, Chaudhary et $\mathrm{al}^{13}(65 \%)$ and $\mathrm{Yu}$ et $\mathrm{al}^{1}(56 \%)$. In our study the corneal astigmatism across all age groups showed a comparable distribution pattern with various previous studies. ${ }^{8,9}$ Knowing the distribution of astigmatism is key in assisting ophthalmologists in selecting the most appropriate first-line care and reducing the incidence of postoperative astigmatism. The treatment options includes incision on steepest meridian ${ }^{15}$, limbal relaxing incisions ${ }^{16}$, opposite clear corneal incisions ${ }^{17}$, excimer laser refractive procedures, femto second laser-assisted astigmatic keratotomy ${ }^{18-20}$ and toric IOL implantation ${ }^{21}$ or combination of these. Though costly, toric IOL implantation can be used to correct up to $8.0 \mathrm{D}$ of corneal astigmatism during cataractsurgery. ${ }^{22}$ In this study, almost $40 \%$ of cataract patients had corneal astigmatism $>1.0 \mathrm{D}$, which could be effectively corrected with toric IOL implantation where as other could be managed by incision on steepest meridian and limbal relaxing incisions at this rural setting.

The mean $\mathrm{AL}$ in the present study is consistent with that reported by Thapa et $\mathrm{al}^{8}$ Baral et $\mathrm{al}^{10}{ }^{10}$, Murchison et $\mathrm{al}^{12}$ and Nauze et $\mathrm{al}^{15}$ but found to have shorter axial length than the report from Chinese population. ${ }^{1}$ Ocular axial length affects other components of the biometric parameters in eyes. In the present study, we observed that as the AL increases, ACD and LT also increases but this relation doesn't hold true for $>26 \mathrm{~mm}$ long eyes. Additionally, the keratometry values (K) decreased when the $A L$ increases. These results are consistent with the findings of previous studies. ${ }^{1,8,22}$ As the WTR is the most common variety of corneal astigmatism; we suggests that when considering high volume camp cataract surgery for patients with a low socioeconomic status in this region, smaller and superior incisions should be used frequently to reduce postoperative astigmatism.

In our study $82.4 \%$ of patients achieve $\geq 6 / 18$ uncorrected visual acuity which is considered as good surgical result as per WHO recommendations ${ }^{6}$ despite of not using any of the modality to correct corneal astigmatism. The poor visual outcome was observed in few patients due to transient surgical complication, preexisting sight impairing ocular diseases including glaucoma and optic atrophy as observed by Bachani et al. ${ }^{5}$

\section{LIMITATIONS}

The short follow up, not considering refractive correction in visual outcome are the limitations of this study. A prospective comparative study with postoperative follow up keeping both corrected and uncorrected visual outcome will help to get more reliable research outcome.

\section{CONCLUSIONS}

The biometric data helps to improve surgical procedure and select most appropriate intraocular lens to attain maximal postoperative uncorrected visual acuity following cataract surgery. This study found superior convention incision is better for cataract surgery with equivalent visual outcome following manual small incision cataract surgery and phacoemulsification.

\section{REFERENCES}

1. Yu J, Zhong J, Mei Z, Zhao F, Tao N and Xiang Y. Evaluation of biometry and corneal astigmatism in cataract surgery patients from Central China. BMC Ophthalmology2017;17:1-7

2. Ruit S, Gurung R, and Vyas $S$. The role of small incision suture-less cataract surgery in the developed world. CurrOpinOphthalmol 2018; 29:105-109

3. Natchiar G, DabralKar T. Manual small incision sutureless cataract surgery; an alternative technique to instrumental phacoemulsification. Operative Tech Cataract Refract Surg 2000; 3:161-170.

4. Olsen T. Improved accuracy of intraocular lens power calculation with the Zeiss IOL Master. Acta Ophthalmol Scand. 2007;85:84-7.

5. Bachani D, Gupta SK, Murthy GV, Jose R. Visual outcomes after cataract surgery and cataract surgical coverage in India. IntOphthalmol. 1999;23(1):49-56.

6. World Health Organization. Informal consultation on analysis of blindness prevention outcomes. Geneva: WHO; 1998

7. Hussen MS, Gebreselassie KL, Seid MA, Belete GT. Visual outcome of cataract surgery at Gondar University Hospital Tertiary Eye Care and Training Center, North West Ethiopia. ClinOptom (Auckl). 2017; 10;9:19-23.

8. Thapa B.B, Dhakal Y., Verma J., Manandhar P. Ocular Biometry and Corneal Astigmatism in Patients Undergoing Cataract Surgery in Bheri Zone of Nepal. Journal of Nepalgunj 
Medical College.2017; 15(2):53-57.

9. Fotedar R, Wang JJ, Burlutsky G, Morgan IG, Rose K, Wong TY, et al. Distribution of axial length and ocular biometry measured using partial coherence laser interferometry (IOL master) in an older white population. Ophthalmology.2010; 117: 417-23.

10. Baral P, Baral N, Maharjan I.M., Gautam B. R.,Bhandari M. Biometric parameters and intra ocular lens power Nepal J Ophthalmol 2014; 6: 192-196.

11. Sherchan A, Kandel R P, Sharma MK, Sapkota YD, Aghajanian $\mathrm{J}$, Bassett K L. Blindness prevalence and cataract surgical coverage in Lumbini Zone and Chitwan District of Nepal. Br J Ophthalmol2010; 94:161-166.

12. Murchison A, Richards M, Tabin G, Ruit S, Gurung R. Optimal single intraocular lens power for the Nepali population. $\mathrm{Br}$ JOphthalmol.2004; 88:1235-1236.

13. Chaudhary M, Dahal HN. Prevalence and types of corneal astigmatism in patients undergoing cataract surgery. Journal of Institute of Medicine, April, 2017, 39:,22-28

14. Chen W, Zuo C, Chen C, Su J, Luo L, Congdon N. Prevalence of corneal astigmatism before cataract surgery in Chinese patients. J Cataract Refract Surg. 2013;39:188-92.

15. NauzeJ L, Thanh TK, Lap TD. Intraocular lens power prediction in a Vietnamese population. Ophthalmic Epidemiol1999;6(3):147-158.

16. Khokhar S, Lohiya P, Murugiesan V, Panda A. Corneal astigmatism correction with opposite clear corneal incisions or single clear corneal incision: comparative analysis. J Cataract Refract Surg. 2006;32:1432-1437.

17. Mendicute J, Irigoyen C, Ruiz M, Illarramendi I, Ferrer-Blasco T, Montes-MicoR. Toric intraocular lens versus opposite clear corneal incisions to correct astigmatism in eyes having cataract surgery. J Cataract Refract Surg. 2009;35:451-8.

18. Gunvant P, Ablamowicz A, Gollamudi S. Predicting the necessity of LASIK enhancement after cataract surgery in patients with multifocal IOL implantation. ClinOphthalmol. 2011;5:1281-5.

19. Norouzi H, Rahmati-Kamel M. Laser in situ keratomileusis for correction of induced astigmatism from cataract surgery. J Refract Surg. 2003;19:416-24.

20. Ruckl T, Dexl AK, Bachernegg A, ReischI V, Riha W, Ruckhofer J.Femtosecond laser-assisted intrastromal arcuate keratotomy to reduce corneal astigmatism. J Cataract Refract Surg. 2013;39:528-38.

21. Bachernegg A, Ruckl T, Riha W, Grabner G, Dexl AK. Rotational stability and visual outcome after implantation of a new toric intraocular lens for the correction of corneal astigmatism during cataract surgery. J Cataract RefractSurg. 2013;39:1390-8.

22. Rubenstein JB, Raciti M. Approaches to corneal astigmatism in cataract surgery. CurrOpinOphthalmol. 2013;24:30-4. 